\title{
ENSINO PRESENCIAL OU ENSINO REMOTO EMERGENCIAL: O QUE PREFEREM E VALORIZAM ESTUDANTES E PROFESSORES DE PROJETO EM ENGENHARIA MECÂNICA
}

\author{
FACE-TO-FACE TEACHING OR EMERGENCY REMOTE TEACHING: WHAT STUDENTS \\ AND PROJECT TEACHERS PREFER AND VALUE IN MECHANICAL ENGINEERING \\ Marina Duarte ${ }^{1}$, Fátima Monteiro² \\ DOI: 10.37702/REE2236-0158.v40p310-320.2021
}

\begin{abstract}
RESUMO
Em março de 2020, a pandemia forçou as Instituições do Ensino Superior portuguesas a adotarem o ensino remoto emergencial suportado por tecnologia digital. Desde então, têm-se sucedido períodos alternados de aulas presenciais e de aulas remotas online (total e parcialmente). No Instituto Superior de Engenharia do Porto (ISEP), em Portugal, e durante os vários estados de emergência decretados pelo governo, todas as aulas foram remotas, passando a ser parcialmente presenciais sempre que o alívio das restrições à circulação de pessoas o permitiu. No caso particular do Departamento de Engenharia Mecânica do ISEP, as aulas teóricas foram sempre remotas, mas as aulas teórico-práticas e práticas-laboratoriais passaram a presenciais sempre que tal foi possível. Por isso, a maioria das aulas que os estudantes de Engenharia Mecânica tiveram entre março de 2020 e julho de 2021 foram remotas. Este estudo tem como objetivo investigar se estudantes e professores de unidades curriculares de projeto consideram o ensino remoto emergencial uma boa alternativa ao ensino presencial, qual a sua preferência e quais as características que as aulas remotas online devem ter para serem uma boa alternativa às aulas presenciais. No caso dos estudantes, o estudo é longitudinal, sendo ainda possível averiguar se as suas perceções mudaram com o passar do tempo e com a frequência de mais aulas de projeto, quer presenciais quer remotas. Os resultados mostram que a maioria dos estudantes considera as aulas remotas uma boa alternativa e gostariam de vê-las substituir as aulas de projeto presenciais; o que não acontece com os professores. Os dados mais recentes mostram que os estudantes valorizam os aspetos que melhor replicam, em ambiente digital, as aulas presenciais, nomeadamente no que respeita a serem síncronas, à interação com o professor em pequenos grupos, a ver e ouvir o professor e poder mostrar-lhe o ecrã do computador. Os dados recolhidos junto dos professores na mesma altura se mostram concordantes com estes.
\end{abstract}

Palavras-chave: COVID-19; ensino remoto emergencial; ensino superior; Educação em Engenharia.

\begin{abstract}
In March 2020, the pandemic forced Portuguese Higher Education Institutions to change to emergency remote teaching. Since then, there have been alternate periods of totally and partially remote classes. In the School of Engineering of Polytechnic of Porto (ISEP), in Portugal, in the emergency states enacted by the government, all classes were remote, being partially in presence

\footnotetext{
${ }^{1}$ Professora adjunta, Engenheira Mecânica, Mestre em Engenharia Mecânica, Doutora em Ciências da Educação, Instituto Superior de Engenharia do Porto - Instituto Politécnico do Porto, Portugal; mic@isep.ipp.pt

${ }^{2}$ Professora adjunta, Engenheira Eletrotécnica, Mestre em Engenharia Eletrotécnica, Doutora em Ciências da Educação, Instituto Superior de Engenharia de Coimbra - Instituto Politécnico de Coimbra; fatcmont@isec.pt
} 
whenever the restrictions to people circulation allowed it. In the case of the Mechanical Engineering Department of ISEP, all theoretical classes have been remote, but the theoretical-practical and practical-laboratorial classes became face-to-face whenever it was possible. Therefore, most of the classes that students of Mechanical Engineering took between March 2020 and July 2021, were remote. This study aims to investigate whether students and teachers consider online classes a good alternative to face-to-face capstone design project classes, if they prefer online classes, and what characteristics these online classes must have to be a good alternative to face-to-face classes. Regarding the students, the study is longitudinal, being also possible to check if their perceptions changed with time. Results show that most students consider online classes a good alternative to faceto-face classes and would like to see them replace face-to-face capstone design project classes, which is not the case with teachers. The most recent data show that students value the aspects that best replicate, in a digital environment, face-to-face classes, particularly regarding synchronous classes, interaction with the teacher in small groups, in being able to show the teacher the computer screen and to hear and see him or her. The data collected from the teachers at the same time show agreement with students.

Keywords: COVID-19; emergency remote teaching; higher education; Engineering Education.

\section{INTRODUÇÃO}

Em março de 2020, a pandemia da COVID-19 forçou as Instituições de Ensino Superior (IES) portuguesas a suspenderem todas as atividades letivas presenciais, por ter sido decretado o estado de emergência (ASSEMBLEIA DA REPÚBLICA, 2020). Perante isso, foi necessário recorrer a comunicação online através de vídeo chamada (Microsoft teams, Zoom, Skype, entre outras), sendo pedido a professores e estudantes que se adaptassem muito rapidamente a essa nova realidade e ao ensino remoto emergencial (HODGES et al., 2020; MOREIRA; HENRIQUES; BARROS, 2020). As aulas passaram assim a ser lecionadas a distância com o suporte de tecnologia digital, sucedendo-se períodos alternados de ensino remoto, de ensino presencial com distanciamento social e de ambos, de acordo com as exigências ditadas pelas sucessivas "ondas" da COVID-19 e pelos correspondentes estados de emergências e calamidade decretados pelo governo (ASSEMBLEIA DA REPÚBLICA, 2020). Em Portugal, a tutela deixou ao critério das IES a definição de como adaptar o ensino às indicações da Direção-Geral da Saúde, de acordo com um conjunto de recomendações que foram sendo emanadas nesse sentido (DIREÇÃO GERAL DO ENSINO SUPERIOR, 2021).

Não obstante o caráter temporário deste ensino remoto emergencial (HODGES et al., 2020), a situação pandêmica dura há mais de um ano, sendo já possível afirmar que os estudantes que entraram em cursos de licenciatura $\left(1^{\circ}\right.$ ciclo de graduação) no ano letivo 2018/2019 fizeram metade do seu curso durante a pandemia $\left(2^{\circ}\right.$ semestre do $2^{\circ}$ ano e $3^{\circ}$ ano completo), tendo estado tanto tempo em ensino remoto emergencial (total ou parcial) quanto em ensino presencial. Por outro lado, a extensão dessa situação também tem permitido que professores e estudantes ajustem as suas práticas, tornando-se mais preparados para esse tipo de ensino, podendo assim aproximá-lo mais do ensino remoto online (não emergencial), nomeadamente no que toca às suas vantagens (MOREIRA; HENRIQUES; BARROS, 2020). Vários autores têm associado várias vantagens ao ensino remoto online, entre as quais se incluem as que são de natureza circunstancial (BEMPOSTA ROSENDE; GARCÍA GARCIIA; ESCRIBANO OTERO, 2011; BLAGA, 2012; CABERO 
ALMENARA, 2006), relacionadas com o espaço e localização (BLAGA, 2019) e o custo (LIAW; HUANG, 2003), e também aquelas que abordam a relação estudante-professor (WAGNER; HASSANEIN; HEAD, 2008). Quanto às desvantagens, estas estão relacionadas com a distância física entre estudantes e professores e entre estudantes, havendo mesmo autores que consideram as aulas presenciais essenciais para o processo de ensino-aprendizagem (YOUNG, 1997). Esse ponto de vista é sustentando porque a Educação em Engenharia tem uma forte componente de prática, particularmente com projetos, sejam eles de natureza mais computacional ou mais experimental (laboratorial), mas também porque alguns autores identificaram a necessidade de os estudantes de engenharia melhorarem as suas competências de comunicação, escuta e escrita (JOHNSTON; LEE; MCGREGOR, 1996; NUSSBAUM, 2014) e de reflexão e empatia (RASOAL; DANIELSSON; JUNGERT, 2012). Conjeturase se as aulas remotas online, ainda que sincronizadas, são vistas por estudantes e professores de projeto como uma alternativa viável para as aulas presenciais.

Este estudo tem como objetivo investigar se estudantes e professores de unidades curriculares de projeto consideram: (i) o ensino remoto emergencial uma boa alternativa ao ensino presencial; (ii) qual a sua preferência; e (iii) quais as características que as aulas na modalidade de ensino remoto emergencial devem ter para serem uma boa alternativa às aulas presenciais. No caso dos estudantes, o estudo é longitudinal, sendo ainda possível averiguar se as suas perceções mudaram com o passar do tempo e com a frequência de mais aulas de projeto, quer presenciais quer remotas.

\section{ENSINO REMOTO EMERGENCIAL}

A designação ensino remoto emergencial nomeia o ensino que resultou da mudança temporária, forçada e imprevista do ensino presencial para um ensino remoto recorrendo a meios tecnológicos e à internet, em resultado da pandemia do Sars-CoV-2 (APPENZELLER et al., 2020). O seu principal objetivo foi garantir a continuidade da formação dos estudantes, assegurando o isolamento social imposto entre estudantes e entre estes e os respectivos professores. No ensino remoto presencial, o foco está sobre os conteúdos e a principal ferramenta é a webconferência (OLIVEIRA; CORRÊA; MORÉS, 2020). Esse modo de ensino distingue-se do ensino a distância quer na sua prática, quer por ter ocorrido de forma imprevista e, como tal, não ter permitido a formação de professores e estudantes, nem o planejamento dos conteúdos, ferramentas e atividades (HODGES et al., 2020). Neste sentido, Morais et al. (2020) salientam que o ensino a distância se fundamenta numa concepção teórica e metodológica específica, recorrendo a ferramentas pedagógicas próprias, na qual os professores tomam o papel de tutores, o que não ocorre no ensino remoto emergencial. Acresce que o ensino a distância tem um caráter robusto e uma perspetiva de funcionamento a longo prazo, ao contrário do ensino remoto emergencial que surgiu, e é perspectivado, como temporário (RONDINI; PEDRO; DUARTE, 2020) e, por isso mesmo, sem a necessidade de ser concebido de forma robusta e estruturada.

Um dos problemas que resultaram da entrada em ensino remoto emergencial foi a garantia de condições de acesso estáveis e equitativas (APPENZELLER et al., 2020; OLIVEIRA; CORRÊA; MORÉS, 2020). Esses problemas foram mais relevantes na fase inicial do funcionamento do ensino remoto emergencial, tendo-se atenuado com o prolongar da situação, em parte por intervenção das IES que procuraram colmatar as necessidades, quer dos estudantes, quer dos professores (APPENZELLER et al., 2020). Tendo em conta a falta de preparação prévia dos professores, Appenzeller et al. (2020) destacam que, na situação de ensino remoto emergencial, estes se sentiram ansiosos e despreparados para o ensino online. Também Oliveira, Corrêa e Morés (2020) salientam a falta de preparação dos professores para ensino a distância, o que motivou o uso instrumental das ferramentas tecnológicas para perpetuar o modo de ensino que lhes era familiar. 
Segundo Moreira, Henriques e Barros (2020) e Oliveira, Corrêa e Morés (2020), o ensino remoto emergencial apenas transferiu e transpôs para a realidade online os modelos de ensino/aprendizagem que eram usados nas práticas presenciais anteriores à pandemia. Para esses investigadores, os professores e estudantes fizeram um grande esforço de adaptação aos suportes digitais de interação, que foram usados de forma instrumental, mas mantendo o perfil de ensino transmissivo e passivo. Moreira, Henriques e Barros (2020), a favor de uma aprendizagem colaborativa e construtivista, defendem que a imposição de mudança imposta pela situação pandêmica deveria ser aproveitada como uma oportunidade de alterar as práticas atuais, incentivando outras que promovam uma aprendizagem ativa, autônoma e reflexiva. Em sintonia, Henriques et al. (2015) alertam que tal alteração implica formação e sensibilização dos professores, uma vez que está em causa uma mudança de paradigma e de filosofia educacional e a apropriação digital. Na situação de ensino remoto emergencial, para que o processo de aprendizagem seja bem-sucedido, é necessário que os estudantes tenham uma postura mais proativa, exercendo mais autonomia e empenho pessoal (OLIVEIRA; CORRÊA; MORÉS, 2020). Mas, também neste aspecto, os autores consideram ser fundamental a formação dos professores com vista à promoção dessas dimensões, mediante uma formação emancipatória. $\mathrm{O}$ ensino remoto assíncrono promove mais a autonomia dos estudantes, contudo também requer maior empenho, autodomínio e gestão de tempo. Por outro lado, o recurso a sessões síncronas proporciona a comunicação e interação entre estudantes e destes com o professor, além de ser mais próximo do ensino presencial. Também incentiva à manutenção de um certo ritmo de estudo/aprendizagem e à criação de laços. $\mathrm{O}$ estudo de Notariano Biotto e Mara Baptista Serra (2020) permitiu concluir que o isolamento imposto devido à situação pandêmica causou impactos na saúde mental

\footnotetext{
${ }^{3} \mathrm{O}$ ensino superior português encontra-se subdividido em dois
} subsistemas: o universitário e o politécnico. dos estudantes e que estes encontraram dificuldades em mobilizar e manter a sua concentração e empenho durante o ensino remoto emergencial. Esses dois aspetos permitem compreender que as sessões síncronas tenham sido a metodologia preferida dos estudantes em alternativa às vantagens do ensino assíncrono. Apesar dos múltiplos problemas que o ensino remoto emergencial revelou, Rondini, Pedro e Duarte (2020) destacam que, devido aos desafios e possibilidades que despertou, esse tipo de ensino acabou por constituir uma mudança tão significativa para estudantes e para professores que mudará a forma de percecionar o processo de ensino/aprendizagem no pós-ensino remoto emergencial. Para esses autores, o ensino remoto emergencial proporcionou $\mathrm{O}$ desenvolvimento de formas criativas de ensino que alargaram os horizontes de professores e estudantes.

\section{CONTEXTO DO ESTUDO}

O Instituto Superior de Engenharia do Porto (ISEP) é uma IES com 169 anos, que pertence ao subsistema politécnico do ensino superior português ${ }^{3}$, estando integrado no Politécnico do Porto. Com mais de 6500 estudantes e cerca de 500 colaboradores, teve em funcionamento, no ano letivo 2019/2020 26 cursos conferentes de grau (14 de licenciatura - cursos de graduação de três anos, e 12 de mestrado - cursos de graduação de dois anos para licenciados), sete cursos técnicos superiores profissionais não conferentes de grau e 26 pós-graduações (INSTITUTO SUPERIOR DE ENGENHARIA DO PORTO, 2020). A área de ensino do ISEP está organizada em departamentos, tendo cabido a estes definir como as aulas presenciais e remotas seriam alternadas/combinadas durante a situação pandêmica. O departamento de Engenharia Mecânica optou por fazê-lo de acordo com a tipologia da aula (teórica, T; teórico-prática, TP; prática-laboratorial, PL). Assim, durante os estados de emergência todas

\footnotetext{
${ }^{4}$ Os dados mais recentes disponíveis reportam-se a este ano letivo
} (2019/2020). 
as aulas foram remotas (síncronas online), e quando as restrições à circulação foram aliviadas, mas ainda era necessário o distanciamento social, as aulas teóricas (T) foram remotas (síncronas online) e as aulas teóricas-práticas (TP) e práticas-laboratoriais (PL) foram presenciais, com um número adaptado de alunos em sala de aula, para garantir a distância de segurança (INSTITUTO POLITÉCNICO DO PORTO, 2021; INSTITUTO SUPERIOR DE ENGENHARIA DO PORTO, 2021b). O departamento é responsável, entre outros cursos, pela licenciatura em Engenharia Mecânica. Essa licenciatura tem três anos (seis semestres com 30 unidades de crédito cada) e 35 unidades curriculares (INSTITUTO SUPERIOR DE ENGENHARIA DO PORTO, 2021a). Destas, três são unidades curriculares de projeto: anteprojeto (ANPRO) no quarto semestre $\left(2^{\circ}\right.$ ano, $2^{\circ}$ semestre); projeto 1 (PROJ1) no quinto semestre ( $3^{\circ}$ ano, $1^{\circ}$ semestre); e projeto/estágio (PESTM) no sexto semestre $\left(3^{\circ}\right.$ ano, $2^{\circ}$ semestre). Projeto/estágio pode ser frequentada na vertente projeto ou na vertente estágio, decorrendo o projeto em sala de aula e o estágio numa entidade acolhedora (INSTITUTO SUPERIOR DE ENGENHARIA DO PORTO, 2021a). Como todas as aulas de projeto são práticas-laboratoriais, os estudantes que ingressaram no ensino superior em 2018/2019 fizeram ANPRO remotamente (sincronamente online), PROJ1 presencialmente (com distanciamento) e PESTM remotamente (sincronamente online) e presencialmente (em proporções idênticas). Por isso, a maioria das aulas que os alunos da licenciatura em Engenharia Mecânica tiveram, entre março de 2020 e julho de 2021, foram remotas síncronas online (ver Tabela 1). De acordo com a informação constante das fichas de unidade curricular (SARMENTO, 2020; 2021; SILVA, 2020), em todas as unidades curriculares de projeto, os alunos trabalham em pequenos grupos (dois a três alunos) e têm uma aula por semana (três horas no caso de ANPRO e PROJ1 e quatro horas no caso de PESTM) que decorre em salas com computadores. São utilizadas principalmente metodologias de ensino semidiretivas e não-diretivas, com destaque para o questionamento.

Tabela 1 - tipo de aulas na licenciatura em Engenharia Mecânica em 2019/20 e 2020/21

\begin{tabular}{lll}
\hline Período & Tipo de aulas & Tipo de ensino \\
\hline $\begin{array}{l}\text { 2019, } \\
\text { setembro a } \\
\text { dezembro }\end{array}$ & Todas as aulas & $\begin{array}{l}\text { Presencial (sem } \\
\text { distanciamento) }\end{array}$ \\
\hline
\end{tabular}

2020, março Todas as aulas Remoto (digital) a junho

\begin{tabular}{lll}
\hline $\begin{array}{l}\text { 2020, } \\
\text { setembro a } \\
\text { dezembro }\end{array}$ & $\begin{array}{l}\text { Aulas T } \\
\text { Aulas TP e PL }\end{array}$ & $\begin{array}{l}\text { Remoto (digital) } \\
\text { Presencial (com } \\
\text { distanciamento) }\end{array}$ \\
\hline $\begin{array}{l}\text { 2021, março } \\
\text { a abril }\end{array}$ & Todas as aulas & Remoto (digital) \\
\hline $\begin{array}{l}\text { 2021, abril } \\
\text { a junho }\end{array}$ & Aulas T & $\begin{array}{l}\text { Remoto (digital) } \\
\text { Aulas TP e PL }\end{array}$ \\
& & $\begin{array}{l}\text { Presencial (com } \\
\text { distanciamento) }\end{array}$ \\
\hline
\end{tabular}

Nota: T-teóricas, TP- teórico-práticas, PL- práticas-laboratoriais. Não foram incluídos os períodos de exames, que decorrem em janeiro e fevereiro ( $1^{\circ}$ semestre) e junho e julho ( $2^{\circ}$ semestre).

Fonte: elaborada pelas autoras.

\section{METODOLOGIA}

A amostra do estudo é constituída por estudantes e professores. No caso dos estudantes, os participantes foram uma amostra de conveniência de uma turma de dezoito alunos de engenharia mecânica ( $2^{\circ}$ ano) que frequentaram a unidade curricular de ANPRO entre março e junho de 2020 ( $2^{\circ}$ semestre do ano letivo 2019/20). Esses estudantes eram maioritariamente do sexo masculino $(73,7 \%)$, como é comum em Engenharia Mecânica, e tinham idades compreendidas entre os 18 e os 20 anos $(68,4 \%)$, o que está de acordo com o ano curricular que frequentam (INSTITUTO SUPERIOR DE ENGENHARIA DO PORTO, 2020). No caso dos professores, estes foram selecionados por terem lecionado ANPRO no ano letivo 2019/20, ou PROJ1 ou PESTM no ano letivo 2020/21. Identificaram-se nove professores nessas condições, tendo sete $(77,8 \%)$ acedido a participar no estudo. Esses professores eram maioritariamente do sexo masculino $(71,4 \%)$ e com idades entre os $51 \mathrm{e}$ os 60 anos $(85,7 \%)$. Para a recolha de dados, foi preparado um questionário eletrônico especificamente para o efeito. Para além de 
uma seção com os dados sociodemográficos e escolares, o questionário tinha duas perguntas de escolha múltipla, com uma única opção de resposta (sim ou não), nas quais se perguntava aos participantes se consideravam que as aulas presenciais de projeto podiam ser substituídas por aulas remotas online e se gostariam que o fossem. Numa terceira pergunta, os participantes eram questionados sobre quais as características que aulas remotas online deveriam ter para poderem ser uma boa alternativa às aulas presenciais, tendo de escolher a partir de uma lista de alternativas (podiam escolher múltiplas alternativas). $\mathrm{O}$ questionário foi o mesmo para os estudantes e para os professores. O convite com o link para aceder ao questionário foi enviado aos estudantes e professores por e-mail. Os participantes foram informados de que a sua participação era voluntária, anônima e confidencial, tendo o estudo respeitado os princípios de ética aplicáveis (COMISSÃO EUROPEIA, 2005; 2018; FUNDAÇÃO PARA A CIÊNCIA E TECNOLOGIA, 2021; SOCIEDADE PORTUGUESA DE CIÊNCIAS DA EDUCAÇÃO, 2020). Os dados dos estudantes foram recolhidos três vezes: em março de 2020 (após a primeira semana de aulas exclusivamente remotas online; $\mathrm{N}=18$ ), em maio 2020 (após dois meses de aulas exclusivamente remotas online; $\mathrm{N}=16$ ), em junho de 2021 (após quase um semestre de aulas exclusivamente remotas online, um semestre completo de um misto de aulas presenciais e remotas online sincronizadas, e um semestre completo de aulas remotas online, como mostra a Tabela $1 ; \mathrm{N}=10$ ). Os dados dos professores foram recolhidos em junho de 2021 $(\mathrm{N}=7)$. Os dados foram descarregados para uma folha de cálculo, tendo-se calculado medidas de estatística descritiva, como frequências e médias.

\section{RESULTADOS}

Sobre se as aulas remotas online poderiam ser consideradas uma boa alternativa às aulas presenciais de projeto, os estudantes começaram por concordar unanimemente que sim, existindo uma ligeira diminuição à medida que o tempo foi decorrendo (cerca de 10\%; ver Tabela 2). Já em relação aos professores, a tendência se inverteu, com a maioria $(85,7 \%)$ a não considerar as aulas remotas como uma boa alternativa.

Tabela 2 - considera que as aulas presenciais de projeto podem ser substituídas por aulas remotas online?

\begin{tabular}{lllll}
\hline \multirow{2}{*}{ Data } & \multicolumn{2}{c}{ Estudantes } & \multicolumn{2}{c}{ Professores } \\
\cline { 2 - 5 } & $\operatorname{Sim}(\%)$ & Não (\%) & $\operatorname{Sim}(\%)$ & Não (\%) \\
\hline $\begin{array}{l}2020, \\
\text { março }\end{array}$ & 100,0 & 0,0 & --- & --- \\
\hline $\begin{array}{l}2020, \\
\text { maio }\end{array}$ & 88,2 & 11,8 & --- & --- \\
\hline $\begin{array}{l}2021, \\
\text { junho }\end{array}$ & 90,0 & 10,0 & 14,3 & 85,7 \\
\hline
\end{tabular}

Nota: Estudantes (2020, março, $\mathrm{N}=18 ; 2020$, maio, $\mathrm{N}=16$; 2021, junho, $\mathrm{N}=10$ ); professores (2021, junho, $\mathrm{N}=7$ )

Fonte: elaborada pelas autoras.

Questionados sobre se gostariam que as aulas presenciais fossem substituídas por aulas remotas online, os estudantes começaram todos por concordar, para depois quase metade $(47 \%)$ mudar de ideias, estabilizando este valor em $30 \%$, à medida que o tempo foi passando (ver Tabela 3). Quanto aos professores, e contrariamente aos estudantes, nenhum $(0,0 \%$; ver Tabela 3) gostaria que as aulas presenciais fossem substituídas por aulas remotas online.

Tabela 3 - gostaria que as aulas presenciais de projeto fossem substituídas por aulas remotas online?

\begin{tabular}{lcccc}
\hline \multirow{2}{*}{ Data } & \multicolumn{2}{c}{ Estudantes } & \multicolumn{2}{c}{ Professores } \\
\cline { 2 - 5 } & Sim (\%) & Não (\%) & Sim (\%) & Não (\%) \\
\hline $\begin{array}{l}2020, \\
\text { março }\end{array}$ & 100,0 & 0,0 & --- & --- \\
\hline $\begin{array}{l}2020, \\
\text { maio }\end{array}$ & 52,9 & 47,1 & --- & --- \\
\hline $\begin{array}{l}2021, \\
\text { junho }\end{array}$ & 70,0 & 30,0 & 0,0 & 100,0 \\
\hline
\end{tabular}

Nota: Estudantes (2020, março, $\mathrm{N}=18 ; 2020$, maio, $\mathrm{N}=16 ; 2021$, junho, $\mathrm{N}=10$ ); professores (2021, junho, $\mathrm{N}=7$ )

Fonte: elaborada pelas autoras.

Relativamente às características que as aulas remotas online deveriam ter para serem uma boa alternativa às aulas presenciais, os estudantes (ver Tabela 4) identificaram sempre 
como prioritárias a comunicação com o professor ocorrer em pequenos grupos de cada vez, com áudio (sem necessidade de vídeo) e com partilha do ecrã do computador. Seguiu-se a comunicação síncrona e o recurso ao vídeo. Com muito menos importância surgia a comunicação com texto, a comunicação do professor com a turma toda simultaneamente e a comunicação assíncrona.

Tabela 4 - na opinião dos estudantes, que características devem ter as aulas remotas síncronas online de projeto para serem uma boa alternativa às gostaria que as aulas presenciais?

\begin{tabular}{|c|c|c|c|c|}
\hline \multirow{2}{*}{$\begin{array}{l}\text { Características do } \\
\text { modo de } \\
\text { comunicar na aula }\end{array}$} & \multicolumn{4}{|c|}{ Estudantes } \\
\hline & $\begin{array}{l}2020, \\
\text { março }\end{array}$ & $\begin{array}{l}2020, \\
\text { maio }\end{array}$ & $\begin{array}{l}\text { 2021, } \\
\text { junho }\end{array}$ & $\begin{array}{c}\mathrm{M} \\
(\%)\end{array}$ \\
\hline $\begin{array}{l}\text { Com o professor } \\
\text { em pequenos } \\
\text { grupos }\end{array}$ & $\begin{array}{l}89,5 \\
\left(1^{\circ}\right)\end{array}$ & $\begin{array}{l}93,8 \\
\left(2^{\circ}\right)\end{array}$ & $\begin{array}{l}100 \\
\left(1^{\circ}\right)\end{array}$ & $\begin{array}{l}93,3 \\
\left(1^{\circ}\right)\end{array}$ \\
\hline $\begin{array}{l}\text { Com áudio (sem } \\
\text { vídeo) }\end{array}$ & $\begin{array}{l}68,4 \\
\left(2^{\circ}\right) \\
\end{array}$ & $\begin{array}{l}87,5 \\
\left(3^{\circ}\right)\end{array}$ & $\begin{array}{l}80,0 \\
\left(2^{\circ}\right)\end{array}$ & $\begin{array}{l}77,8 \\
\left(2^{\circ}\right) \\
\end{array}$ \\
\hline $\begin{array}{l}\text { Com partilha do } \\
\text { ecrã do } \\
\text { computador }\end{array}$ & $\begin{array}{l}57,9 \\
\left(3^{\circ}\right)\end{array}$ & $\begin{array}{l}100 \\
\left(1^{\circ}\right)\end{array}$ & $\begin{array}{l}70,0 \\
\left(3^{\circ}\right)\end{array}$ & $\begin{array}{l}75,6 \\
\left(3^{\circ}\right)\end{array}$ \\
\hline Sincronamente & $\begin{array}{l}57,9 \\
\left(3^{\circ}\right) \\
\end{array}$ & 68,8 & $\begin{array}{l}80,0 \\
\left(2^{\circ}\right) \\
\end{array}$ & 66,7 \\
\hline $\begin{array}{l}\text { Com vídeo (inclui } \\
\text { áudio) }\end{array}$ & 26,3 & 62,5 & $\begin{array}{l}80,0 \\
\left(2^{\circ}\right)\end{array}$ & 51,1 \\
\hline Com texto & 21,1 & 6,3 & 0,0 & 11,1 \\
\hline $\begin{array}{l}\text { Com a turma toda } \\
\text { em simultâneo }\end{array}$ & 5,3 & 0,0 & 30,0 & 8,9 \\
\hline Assincronamente & 0,0 & 18,8 & 0,0 & 6,7 \\
\hline
\end{tabular}

Nota: Estudantes (2020, março, $\mathrm{N}=18 ; 2020$, maio, $\mathrm{N}=16 ; 2021$, junho, $\mathrm{N}=10$ ). $\mathrm{M}$ - média.

Fonte: elaborada pelas autoras.

Os professores (ver Tabela 5) atribuíram mais importância à comunicação em pequenos grupos, com partilha do ecrã de computador e com vídeo, seguida da comunicação síncrona e com toda a turma simultaneamente. Nenhum professor considerou a comunicação apenas com áudio uma característica relevante. Dois dos professores optaram por não responder a esta questão por considerarem que as aulas remotas online não eram uma boa alternativa às aulas presenciais.
Tabela 5 - na opinião dos professores, que características devem ter as aulas remotas síncronas online de projeto para serem uma boa alternativa às gostaria que as aulas presenciais?

\begin{tabular}{|c|c|c|c|c|}
\hline \multirow{2}{*}{$\begin{array}{l}\text { Características do } \\
\text { modo de } \\
\text { comunicar na aula }\end{array}$} & \multicolumn{4}{|c|}{ Professores } \\
\hline & $\begin{array}{l}2020 \\
\text { março }\end{array}$ & $\begin{array}{l}2020, \\
\text { maio }\end{array}$ & $\begin{array}{l}2021, \\
\text { junho }\end{array}$ & $\begin{array}{c}\mathrm{M} \\
(\%)\end{array}$ \\
\hline $\begin{array}{l}\text { Com o professor } \\
\text { em pequenos } \\
\text { grupos }\end{array}$ & --- & --- & $\begin{array}{l}57,1 \\
\left(1^{\circ}\right)\end{array}$ & $\begin{array}{l}57,1 \\
\left(1^{\circ}\right)\end{array}$ \\
\hline $\begin{array}{l}\text { Com áudio (sem } \\
\text { vídeo) }\end{array}$ & --- & --- & 0,0 & 0,0 \\
\hline $\begin{array}{l}\text { Com partilha do } \\
\text { ecrã do } \\
\text { computador }\end{array}$ & --- & --- & $\begin{array}{l}57,1 \\
\left(1^{\circ}\right)\end{array}$ & $\begin{array}{l}57,1 \\
\left(1^{\circ}\right)\end{array}$ \\
\hline Sincronamente & --- & --- & $\begin{array}{l}42,8 \\
\left(2^{\circ}\right)\end{array}$ & $\begin{array}{l}42,8 \\
\left(2^{\circ}\right) \\
\end{array}$ \\
\hline $\begin{array}{l}\text { Com vídeo (inclui } \\
\text { áudio) }\end{array}$ & --- & --- & $\begin{array}{l}57,1 \\
\left(1^{\circ}\right) \\
\end{array}$ & $\begin{array}{l}57,1 \\
\left(1^{\circ}\right) \\
\end{array}$ \\
\hline Com texto & --- & --- & $\begin{array}{l}14,3 \\
\left(3^{\circ}\right) \\
\end{array}$ & $\begin{array}{l}14,3 \\
\left(3^{\circ}\right) \\
\end{array}$ \\
\hline $\begin{array}{l}\text { Com a turma toda } \\
\text { em simultâneo }\end{array}$ & --- & --- & $\begin{array}{l}42,8 \\
\left(2^{\circ}\right)\end{array}$ & $\begin{array}{l}42,8 \\
\left(2^{\circ}\right)\end{array}$ \\
\hline Assincronamente & & & $\begin{array}{l}14,3 \\
\left(3^{\circ}\right)\end{array}$ & $\begin{array}{l}14,3 \\
\left(3^{\circ}\right)\end{array}$ \\
\hline
\end{tabular}

\section{CONCLUSÕES}

A maioria dos estudantes de Engenharia Mecânica que participaram neste estudo consideram as aulas remotas online uma boa alternativa às aulas presenciais de projeto e gostariam que estas aulas fossem substituídas por aulas remotas online. Com o passar do tempo, essa opinião alterou-se para $30 \%$ dos estudantes, que, embora reconhecendo que as aulas presenciais de projeto podem ser substituídas por aulas remotas online, não gostariam que isso acontecesse, preferindo as aulas presenciais. Os professores têm uma opinião distinta, no sentido de não considerarem as aulas remotas online uma boa alternativa às aulas presenciais, preferindo estas últimas. Isso poderia ser um indicador de que estes valorizam muito o relacionamento pessoal e presencial e a linguagem não verbal, ou de que não se sentem confortáveis nesse novo papel ou ambiente digital. Tal poderia, ainda, dever-se à 
falta de formação pedagógica dos professores para esse tipo de ensino (APPENZELLER et al., 2020; OLIVEIRA; CORRÊA; MORÉS, 2020), mas seriam necessários mais estudos para o averiguar. Pode-se assim concluir que esses estudantes estão mais satisfeitos com as aulas remotas online de projeto do que os professores que as lecionaram.

Quanto às características das aulas remotas online de projeto que os estudantes valorizam, o destaque vai para o envolvimento com o professor em pequenos grupos, replicando a metodologia de interação em grupo das aulas presenciais. No caso das aulas de projeto, com grande suporte informático, esperava-se que fosse valorizada a possibilidade de partilhar o ecrã (com o professor), o que aconteceu, embora existam grandes flutuações, o que seria necessário averiguar. Embora não seja uma das características mais valorizadas (em média, ocupa a quarta posição em oito), a comunicação sincronizada vê a sua importância reconhecida com o passar do tempo (aumento de $22,1 \%$ ). O vídeo é inicialmente subvalorizado, em comparação com o áudio, mas é a característica que sofre o maior aumento $(53,7 \%)$, o que pode indicar que a passagem do tempo leva os estudantes a sentirem a falta da linguagem não verbal. Em suma, as características mais e menos valorizadas pelos estudantes permanecem relativamente estáveis, sendo nas características medianamente valorizadas que ocorrem as maiores variações (aumentos). Analisando a recolha de dados mais recente, percebe-se que, com o tempo, os estudantes tendem a valorizar os aspectos que melhor replicam remotamente e online as aulas presenciais, nomeadamente no que respeita a estas ocorrerem sincronamente, a interação com o professor em pequenos grupos, ao poder ouvir e ver o professor e mostrar-lhe o ecrã de computador. Contudo, isso não é suficiente para mudar a sua opinião relativamente à maioritariamente expressa preferência pelas aulas remotas online, indicando que os estudantes reconhecem as vantagens que a literatura tem indicado nesse tipo de ensino (BEMPOSTA ROSENDE; GARCÍA GARCÍA; ESCRIBANO OTERO, 2011; BLAGA, 2012; 2019; CABERO
ALMENARA, 2006; LIAW; HUANG, 2003; WAGNER; HASSANEIN; HEAD, 2008), procurando combiná-las com outras mais associadas às aulas presenciais. Na prática, os estudantes preferem a opção que lhes permite usufruírem do melhor do ensino remoto (eventualmente a flexibilidade de localização; não haver perda de tempo e custos nas deslocações) e do ensino presencial (manter a interação com o professor e os colegas; manter um ritmo fixo e imposto de trabalho/estudo; poder esclarecer dúvidas no momento; manter os relacionamentos sociais e o sentido de pertença à turma). Os dados recolhidos junto dos professores na mesma altura se mostram concordantes com os dos estudantes, no sentido de que os professores também valorizam o que é valorizado pelos estudantes. Contudo, os professores atribuem mais importância do que os estudantes à possibilidade de interagiram com toda a turma em simultâneo.

Em suma, e decorrido mais de um ano de situação pandêmica, os estudantes e os professores estão, no geral, de acordo quanto às características que tornam uma aula remota online uma boa alternativa para as aulas presenciais. Contudo, enquanto os professores não consideram essas aulas uma boa alternativa às aulas presenciais, nem gostariam que as aulas decorressem desse modo, a maioria dos estudantes consideraram-nas uma boa alternativa e gostariam que as aulas de projeto decorressem remotamente e online. Assim, e tal como Rondini, Pedro e Duarte (2020) alertaram, há indícios de uma mudança na perspectiva dos estudantes sobre a forma de encarar o ensino tradicional presencial face ao ensino remoto online, o que poderá abrir novas oportunidades para mudar o ensino/ aprendizagem, o que deverá ser tido em conta quer pelos professores, quer pelas IES.

\section{AGRADECIMENTOS}

Este trabalho é apoiado por fundos nacionais através da FCT - Fundação para a Ciência e a Tecnologia, I.P., no âmbito do financiamento plurianual 2020-2023 atribuído ao CIIE - Centro de Investigação e Intervenção 
Educativas da universidade do Porto [referência UIDB/00167/2020 e UIDP/00167/2020].

\section{REFERÊNCIAS}

APPENZELLER, S. et al. Novos Tempos, Novos Desafios: Estratégias para Equidade de Acesso ao Ensino Remoto Emergencial. Revista Brasileira de Educação Médica, [s.1.], v. 44, n. suppl 1, 2020.

ASSEMBLEIA DA REPÚBLICA. Estado de emergência | COVID-19. 2020. Disponível em:

<https://www.parlamento.pt/Paginas/covid19. aspx>. Acesso em: 29 nov. 2020.

BEMPOSTA ROSENDE, S.; GARCÍA GARCÍA, M. J.; ESCRIBANO OTERO, J. J. B-Learning Under Examination: Advantages, Disadvantages and Opinions. Higher Learning Research Communications, [s.l.], v. 1, n. 1, p. 43-59, 2011.

BLAGA, P. E-learning - a new paradigm for education and training of human resources. Anais... The Proceedings of the Communication, context, interdisciplinarity Congress (Vol. 2). Tîrgu-Mureş: «Petru Maior» University of Tîrgu Mureş, 2012. Disponível em: <https://old.upm.ro/cci12/volCCI_II/Pages from Volum_texteCCI2-139.pdf >.

. Ethical Considerations in Human Resource Training Based on E-Learning. Curentul Juridic, The Juridical Current, Le Courant Juridique, [s.1.], v. 79, p. 42-51, 2019.

CABERO ALMENARA, J. Bases pedagógicas del e-learning. RUSC. Universities and knowledge society journal, [s.l.], vol. 3, n. 1, 2006.

\section{COMISSÃO EUROPEIA. Carta Europeia do} Investigador. Código de Conduta para o Recrutamento de Investigadores. Luxembourg: Office des publications officielles des Communautés européennes, 2005. Disponível em : $<$ https://cdn4.euraxess.org/sites/default/files/b rochures/eur_21620_en-pt.pdf >.
Regulamento Geral sobre a Proteção de Dados (Perguntas e Respostas). 2018. Disponível em: <https://ec.europa.eu/commission/presscorner /detail/pt/MEMO_18_387>.

DIREÇÃO GERAL DO ENSINO SUPERIOR. COVID-19 | AVISOS | DGES. 2021. Disponível em: $<$ https://www.dges.gov.pt/pt/pagina/covid-19avisos>. Acesso em: 20 jun. 2021.

FUNDAÇÃO PARA A CIÊNCIA E TECNOLOGIA. Guia de Ética: concurso para atribuição de bolsas de investigação para doutoramento - 2021. [s.l.]: Fundação para a Ciência e Tecnologia, 2021. Disponível em:

<https://www.fct.pt/apoios/bolsas/concursos/d ocs/Bolsas_2021_GuiaEtica_PT.pdf $>$.

HENRIQUES, S. et al. Online Training of Trainers from the Open University, Portugal. Anais... Expanding Learning Scenarios, Opening Out the Educational Landscape - Proceedings of the European Distance and E-Learning Network 2015 Annual Conference [s.1.]: European Distance and E-Learning Network, 2015. Disponível em: <https://www.edenonline.org/proc-

2485/index.php/PROC/article/view/1428/113 6>.

HODGES, C. et al. The Difference Between Emergency Remote Teaching and Online Learning | EDUCAUSE. Educause review. Educause, 2020. Disponível em: $<$ https://er.educause.edu/articles/2020/3/thedifference-between-emergency-remoteteaching-and-online-learning>. Acesso em 09 jul. 2021.

INSTITUTO POLITÉCNICO DO PORTO. P.PORTO COVID-19. 2021. Disponível em: <https://www.ipp.pt/covid19/plano.html >. Acesso em: 20 jun. 2021.

INSTITUTO SUPERIOR DE ENGENHARIA DO PORTO. Relatório de Atividades do ano 2019/2020. Porto: [s.n.], 2020. Disponível em: <https://www.isep.ipp.pt/ISEP/DocPub>.

Licenciatura em Engenharia Mecânica. 2021a. Disponível em: 
<https://www.isep.ipp.pt/Course/Course/27>. Acesso em: 20 jun. 2021.

\section{em:}

Plano de contingência. 2021b. Disponível

$<$ https://www.isep.ipp.pt/New/ViewNew/623

3>. Acesso em: 20 jun. 2021.

JOHNSTON, S.; LEE, A.; MCGREGOR, H. Engineering as captive discourse. Society for Philosophy and Technology Quarterly Electronic Journal, [s.l.], vol. 1, n. 3/4, p. 128-136, 1996.

LIAW, S.; HUANG, H.-M. Exploring the World Wide Web for Online Learning: A Perspective from Taiwan. Educational Technology, [s.l.], vol. 43, n. 3, p. 27-32, 2003.

MORAIS, I. R. D. et al. Ensino remoto emergencial: orientações básicas para elaboração do plano de aula. [s.l.]: SEDIS/UFRN, 2020.

MOREIRA, J. A. M.; HENRIQUES, S.; BARROS, D. Transitando de um ensino remoto emergencial para uma educação digital em rede, em tempos de pandemia. Dialogia [s.l.], n. 34 , p. $351-364,2020$.

NOTARIANO BIOTTO, C.; MARA BAPTISTA SERRA, S. Experiência de ensino remoto emergencial na pós-graduação em engenharia. Anais... Proceedings of the XLVIII Brasilian Congress of Engineering Education. [s.1.]: Associação Brasileira de Educação em Engenharia, 2020. Disponível em: $<$ http://abenge.org.br/sis_artigo_doi.php?e $=\mathrm{C}$ OBENGE \&a $=20 \& c=3232>$.
NUSSBAUM, M. C. Educação e Justiça Social. [s.l.]: Edições Pedago, 2014.

OLIVEIRA, R. M. De; CORRÊA, Y.; MORÉS, A. Ensino remoto emergencial em tempos de covid-19: formação docente e tecnologias digitais. Revista Internacional de Formação de professores, [s.1.], vol. 5, p. 1-18, 2020.

RASOAL, C.; DANIELSSON, H.; JUNGERT, T. Empathy among students in engineering programmes. European Journal of Engineering Education, [s.1.], vol. 37, n. 5, p. 427-435, 2012.

RONDINI, C. A.; PEDRO, K. M.; DUARTE, C. dos S. Pandemia do Covid-19 e o ensino remoto emergencial: mudanças na práxis docente. Interfaces Científicas - Educação, [s.l.], vol. 10, n. 1, p. 41-57, 2020.

SOCIEDADE PORTUGUESA DE CIÊNCIAS DA EDUCAÇÃO. Carta Ética. $2^{a}$ edição ed. Porto: Sociedade Portuguesa de Ciências da Educação, 2020.

WAGNER, N.; HASSANEIN, K.; HEAD, M. Who is responsible for e-learning success in higher education? A stakeholders' analysis. Journal of Educational Technology \& Society, [s.l.], vol. 11, n. 3 , p. 26-36, 2008.

YOUNG, J. R. Rethinking the Role of the Professor in an Age of High-Tech Tools. Chronicle of Higher Education, [s.1.], vol. 44, n. 6, 1997.

\section{DADOS BIOGRÁFICOS DOS AUTORES}

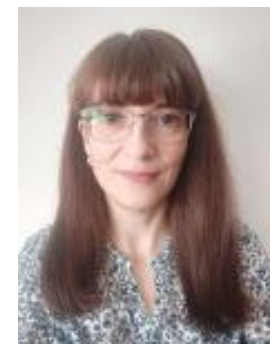

Marina Isabel Felizardo Correia Duarte - Professora Adjunta no Departamento de Engenharia Mecânica do Instituto Superior de Engenharia do Porto do Instituto Politécnico do Porto, em Portugal, onde leciona há quase 30 anos. É licenciada em Engenharia Mecânica, na opção de Fluidos e Calor, pela Faculdade de Engenharia da Universidade do Porto (FEUP), Portugal, e mestre em Engenharia Mecânica, especialização de Engenharia Térmica, pela FEUP, Portugal. É também mestre em Ciências da Educação, especialização em Pedagogia Universitária, pela Faculdade de Psicologia e Ciências da Educação da Universidade de Coimbra, Portugal e Doutorada em Ciências da Educação pela Faculdade de Psicologia e Ciências da Educação da Universidade do Porto, Portugal. É membro integrado do CIIE-Centro 


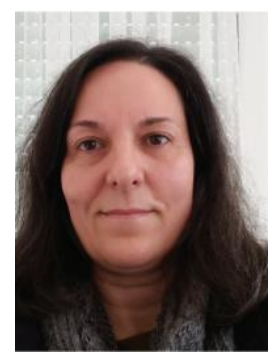

de Investigação e Intervenção Educativas da Faculdade de psicologia e Ciências da Educação da Universidade do Porto. É membro do Colégio de Engenharia Mecânica da Ordem dos Engenheiros Portuguesa e membro da Sociedade Portuguesa da Educação em Engenharia.

Maria de Fátima Coelho Monteiro - Professora Adjunta no Departamento de Engenharia Eletrotécnica do Instituto Superior de Engenharia de Coimbra do Instituto Politécnico de Coimbra, em Portugal, onde leciona há 25 anos. É Licenciada e Mestre em Engenharia Eletrotécnica e de Computadores, pela Faculdade de Engenharia da Universidade do Porto (FEUP), Portugal. Tem o curso de Mestrado em Educação e Formação de Adultos pela Faculdade de Psicologia e Ciências da Educação da Universidade do Porto, Portugal. É Doutorada em Ciências da Educação pela Faculdade de Psicologia e Ciências da Educação da Universidade do Porto, Portugal. É membro da Sociedade Portuguesa da Educação em Engenharia e do Grupo de Trabalho Ética na Educação em Engenharia (GT-EEE). 